\title{
Heat treatment of silanized feldspathic ceramic: Effect on the bond strength to resin after thermocycling
}

\author{
Viviane Maria Gonçalves de Figueiredo ${ }^{\mathrm{a}}$, Pedro Henrique Corazza ${ }^{\mathrm{b}}$, \\ Laura Soares Souto Lepesqueur ${ }^{\mathrm{a}}$, Geraldo M. Miranda ${ }^{\mathrm{c}}$, Clovis Pagani ${ }^{\mathrm{c}}$, \\ Renata Marques de Melo a , Luiz Felipe Valandro ${ }^{\mathrm{d}, *}$ \\ ${ }^{a}$ Department of Dental Materials and Prosthodontics, Institute of Science and Technology of São José dos Campos, São Paulo State University (UNESP), Street \\ Francisco José Longo, No. 777, Jardim São Dimas, São José dos Campos, CEP 12245-000 São Paulo, Brazil \\ b Post-graduation Program in Dentistry, Dental School, University of Passo Fundo, BR 285, Km 171, Passo Fundo, CEP $99001-970$ Rio Grande do Sul, Brazil \\ ${ }^{\mathrm{c}}$ Department of Restorative Dentistry, Institute of Science and Technology of São José dos Campos, São Paulo State University (UNESP), Av. José Longo, No. \\ 777, Jardim São Dimas, São José dos Campos, CEP 12245-000 São Paulo, Brazil \\ d Prosthodontics Unit, Faculty of Odontology, Federal University of Santa Maria, Brazil Street Floriano Peixoto, 1184, 97015-372 Santa Maria, Rio Grande do \\ Sul, Brazil
}

\section{A R T I C L E I N F O}

\section{Article history:}

Accepted 10 August 2015

Available online 28 August 2015

Keywords:

Feldspathic ceramics

Silane

Heat treatment

Microtensile test

Thermocycling

\begin{abstract}
A B S T R A C T
Purpose: This study aimed to evaluate the effect of heat treatment (at $77^{\circ} \mathrm{C}$ ) of a silanized feldspathic ceramic on microtensile bond strength ( $\mu \mathrm{TBS}$ ) with a resin cement before and after being aged by thermocycling.

Material and methods: Twenty-four blocks $\left(12 \times 10 \times 4 \mathrm{~mm}^{3}\right)$ of a CAD/CAM feldspathic ceramic (Vitablocks Mark II, Vita) were obtained and randomly divided into three groups, according to the surface treatment prior to the cementation: Group AS - hydrofluoric acid 10\%+silane; Group S77 - silane + heating at $77^{\circ} \mathrm{C}$ for $60 \mathrm{~s}$; and Group AS77 - hydrofluoric acid $10 \%+$ silane + heating at $77{ }^{\circ} \mathrm{C}$ for $60 \mathrm{~s}$. Ceramic blocks were cemented to composite resin blocks with a resin cement. The sets were subsequently cross-sectioned into $1 \mathrm{~mm}^{2}$ beams for $\mu$ TBS testing. The beams of each group were randomly divided into two subgroups: aging (thermocycling, 12,000 cycles between $5{ }^{\circ} \mathrm{C}$ and $55^{\circ} \mathrm{C}$ ) and non-aging (tested immediately). One-way ANOVA and Tukey's test $(\alpha=0.05)$ and Weibull analysis $(95 \% \mathrm{CI})$ were used to analyze the data.

Results: Group AS77 had the lowest pre-test failure number during the cutting among the groups. There was no significant difference $(p=0.255)$ between the $\mu$ TBS mean values of the non-aged groups. After aging, the mean value of S77 was significantly lower than those of AS77 and AS $(p=0.005)$. There was no difference in the Weibull modulus $(m)$ and characteristic strength $\left(\sigma_{0}\right)$ of the aged and non-aged groups for all comparisons. Before aging, heat treatment of silanized feldspathic ceramic (non acid-etched surface) demonstrated bond strength similar to that achieved with hydrofluoric-acid-etching treatment however, it had lower bond strength after aging.

Conclusion: The combination of hydrofluoric-acid-etching treatment with heat treatment silanized feldspathic ceramic did not improve the bond strength of the interface.
\end{abstract}

(c) 2015 Elsevier Ltd. All rights reserved.

\section{Introduction}

Feldspathic ceramic has been used in dental restorations mainly due to the excellent long-term esthetics provided by its color stability. The established surface treatment for this class of ceramic to bond with resin cements is the 'hydrofluoric acid etching + silane coupling agent application' [1-3]. Surface etching with hydrofluoric acid promotes roughness on the ceramic [1],

\footnotetext{
* Corresponding author. Tel.: +55 553220 9276; fax: +55 5532209272

E-mail address: Ifvalandro@hotmail.com (L.F. Valandro).
}

favoring micromechanical interlocking, and also improves the wettability of the silane on the ceramic surface, by energy surface modification [4]. Nevertheless, the use of hydrofluoric acid has been questioned in some studies, mainly due to its chemical toxicity and hazardous effects, but also due to the formation of insoluble salts that can affect bond strength [3,5-11]. Therefore, alternative treatments for bonding to these ceramics have been proposed, as silane heating in air stream [5,6,12,13] or oven [14-17], and bath in hot water [17]. These temperature-based treatments have the ability to eliminate solvents of the material and enhance the crosslink reaction, favoring the bonding [17]. 
The silane coupling agent consists of a bifunctional molecule with an organic side (reacts with resins and promotes the formation of oligomers) and an inorganic side (reacts with metal oxides and silica of the ceramic glass phase). This characteristic is responsible for cement/ceramic chemical bonding $[1,3,4,6,18]$. The greater the interaction of the silane molecules on the ceramic surface, the better the bond strength of the system and the resistance to degradation of the silane film $[18,19]$. After final condensation, the silane film is basically composed of three structurally and physicochemically different layers: (a) an outer layer, in which silane molecules are weakly attached, with few siloxane bonds that are easily hydrolyzed and removed; (b) a middle layer, in which molecules have strong siloxane bonds that are more resistant to hydrolysis and can be removed only with a hot water bath; and (c) an inner layer, in which the silane is considered chemically reactive [20].

Studies testing the bond strength of the ceramic/resin interface have shown positive results of heat treatment of the silane layer before cementation $[5,6,8,12,15,17,21]$. Specifically, silane heat treatment at $77{ }^{\circ} \mathrm{C}$ (solvent evaporation temperature) increased the bond strength between the ceramic and resin cement compared with that achieved by conventional treatment, even after mechanical aging, showing the stability of the technique after short-term mechanical cycling [17]. However, the literature lacks studies concerning the real effect of temperature (hot air without the association of an air spray), mainly after aging by thermocycling, on the bond strengths between feldspathic ceramic and resin cement. Moreover, the association of heat treatment with the conventional protocol after aging, designed to improve bond strength, should be tested. Therefore, the aim of this study is to evaluate the effect of a $77^{\circ} \mathrm{C}$ heat treatment of a silanized feldspathic ceramic on the microtensile bond strength ( $\mu \mathrm{TBS})$ with a resin cement before and after being aged by thermocycling. The null hypotheses are: (1) the heat treatment does not affect the bond strength; (2) the combination of the hydrofluoric-acid-etching treatment with heat treatment does not improve the bond strength; and (3) the thermocycling does not affect the reliability of the interfaces.

\section{Materials and methods}

\subsection{Materials of study}

The materials used in this study are described in Table 1.

\subsection{Specimen preparation}

Six blocks of a feldspathic ceramic for CAD/CAM (Vitablocks Mark II) with dimensions of $12 \times 10 \times 17 \mathrm{~mm}^{3}$ were sectioned in a cutting machine (Isomet 1000, Buehler Ltd., Lake Bluff, IL, USA), resulting in 24 ceramic blocks $\left(12 \times 10 \times 4 \mathrm{~mm}^{3}\right)$. All blocks were ground-finished for surface standardization with 600 -grit wet silicon carbide papers (3M ESPE, St. Paul, MN, USA). The blocks were molded using a silicone impression material (Elite HD, Zhermack, Badia-Polesine, Rovigo, Italy), and the mold was used to the construction of the composite resin blocks (Z100, A1 shade) which were cemented onto the ceramic surfaces. The composite resin was incrementally applied to the mold ( $2 \mathrm{~mm}$ thickness for each increment), and each increment was light-cured for $40 \mathrm{~s}$ (XL 3000, 3M/ESPE; light intensity $=500 \mathrm{~mW} / \mathrm{cm}^{2}$ ) at a distance of $10 \mathrm{~mm}$, until the total fulfillment of the mold. Light intensity was verified by radiometry so that it was no lower than $500 \mathrm{~mW} / \mathrm{cm}^{2}$. The composite resin blocks were made on the day of cementation. The final dimension of the composite resin blocks was similar to the ceramic blocks.

\subsection{Surface treatment}

The ceramic blocks were ultrasonically cleaned in distilled water for $5 \mathrm{~min}$, and randomly divided into three groups, according to the surface treatment:

- Group AS - The ceramic surface was etched with $10 \%$ HF for $60 \mathrm{~s}$, washed, and air-dried for $30 \mathrm{~s}$. The silane coupling agent was applied by means of a microbrush (3M ESPE) for $60 \mathrm{~s}$ and gently dried with air spray for $15 \mathrm{~s}$.

- Group S77 - The silane coupling agent was applied to the surface by means of a microbrush for $60 \mathrm{~s}$ and gently dried with air spray for $15 \mathrm{~s}$. The silanized block was placed in a $77^{\circ} \mathrm{C}$ preheated oven for $60 \mathrm{~s}$.

- Group AS77 - The ceramic surface was etched with $10 \%$ HF for $60 \mathrm{~s}$, washed, and air-dried for $30 \mathrm{~s}$. The silane coupling agent was applied by means of a microbrush for $60 \mathrm{~s}$ and gently dried with air spray for $15 \mathrm{~s}$. The silanized block was placed in a $77^{\circ} \mathrm{C}$ preheated oven for $60 \mathrm{~s}$.

\subsection{Specimens cemetation}

After the treatments, the blocks of resin composite were cemented onto the ceramic blocks by means of a resin cement (Variolink II), with a constant pressure of $750 \mathrm{~g}$ for $60 \mathrm{~s}$. The excess cement was removed, and the set was light-cured for $40 \mathrm{~s}$ on each side. All sets were stored in distilled water at $37^{\circ} \mathrm{C}$ for $24 \mathrm{~h}$ before the sticks obtaining.

\subsection{Beams preparation}

The ceramic/resin sets were embedded in chemically cured acrylic resin, positioned in a cutting machine (Isomet, Buehler), and sectioned at low speed with water cooling. Each set was longitudinally cut into a series of 1.0 -mm-thick slices and then rotated $90^{\circ}$ for a second sectioning. Approximately 68 beams with (cross-section, area of $1.0 \mathrm{~mm}^{2}$ ) were obtained from each set. The edge sections (measuring approximately $1 \mathrm{~mm}$ ) were discarded due to the possibility of excess or no cement at the interface,

Table 1

Brand name, material type, manufacturer and composition of the materials used in the study.

\begin{tabular}{|c|c|c|c|}
\hline Brand name & Material type & Manufacture & Composition \\
\hline Vitablocks Mark II & Feldspathic ceramic & $\begin{array}{l}\text { VITA Zanhfabrik; Bad Säckin- } \\
\text { gen, Germany }\end{array}$ & Feldspathic cristaline particles $\left(\mathrm{SiO}_{2}, \mathrm{Al}_{2} \mathrm{O}_{3}, \mathrm{Na}_{2} \mathrm{O}, \mathrm{K}_{2} \mathrm{O}\right)$ in glassy matrix \\
\hline Monobond S & $\begin{array}{l}\text { Silane coupling } \\
\text { agent }\end{array}$ & $\begin{array}{l}\text { Ivoclar Vivadent; Schaan, } \\
\text { Leichtenstein }\end{array}$ & 1\% 3-methacryloxypropyl trimethoxysilane (3-MPS) ethanol/water-based solvent \\
\hline Porcelain Conditioner & Acid etchant & Dentsply; Petropolis, Brasil & Hydrofuoric acid (HF) $10 \%$ \\
\hline Variolink II & Resin Cement & $\begin{array}{l}\text { Ivoclar Vivadent, Schaan, } \\
\text { Leichtenstein }\end{array}$ & $\begin{array}{l}\text { Monomer matrix: Bis-GMA, urethane, dimethacrylate and triethylene glycol dimetha- } \\
\text { crylate. Inorganic fillers: barium glass, ytterbium trifluoride, Ba-Al-fluorosilicate glass and } \\
\text { spheroid mixed oxide }\end{array}$ \\
\hline Z100 & Composite resin & 3M ESPE; St Paul, MN, USA & Bis-GMA, TEGDMA, zirconia/silica $(0,6 \mu \mathrm{m})$ \\
\hline
\end{tabular}


which could alter the results. The specimens from each set of ceramic/resin were randomly divided into two subgroups: aging and non-aging. Aging was performed in a thermocycling machine (MSCT-3 Plus, Erios, São Paulo, Brazil): 12,000 cycles were completed between $5 \pm 1{ }^{\circ} \mathrm{C}$ and $55 \pm 1{ }^{\circ} \mathrm{C}$, with $30 \mathrm{~s}$ for each bath. The specimens that were not subjected to the aging process were tested immediately after being sectioned.

\subsection{Microtensile bond strength test}

The beams' bonding area was measured with a digital caliper (Starret Industria e Comercio Ltda, Itu, Brazil). Each beam was fixed to a testing device by means of cyanoacrylate gel (Super Bonder Gel, Loctite Ltda, São Paulo, Brazil) as parallel as possible to the long axis of the device, which was fixed in a universal testing machine (DL-1000, EMIC, São José dos Pinhais, Brazil). The beams were loaded for tensile testing at a crosshead speed of $1 \mathrm{~mm} / \mathrm{min}$ with a $50 \mathrm{kgf}$ load cell until failure. Microtensile bond strength ( $\mu \mathrm{TBS}$ ) was calculated according to the equation $R=F / A$, where $R$ is the strength (MPa), $F$ is the load $(\mathrm{N})$ required to fracture the specimen, and $A$ is the bonding area $\left(\mathrm{mm}^{2}\right)$.

\subsection{Failure analysis}

The fractured sticks were analyzed by stereomicroscopy (Discovery V-20, Carl Zeiss, Göttingen, Germany), and representative beams were examined by scanning electron microscopy (Inspect S50, FEI Company, Orlando, EUA). The fracture types were classified

\section{Table 2}

Number of blocks and sticks of the experimental groups, number and percentage of pre-test failures (PTF) during cutting and during aging, and total number of beams tested.

\begin{tabular}{|c|c|c|c|c|c|c|}
\hline Group & Blocks & Beams & $\begin{array}{l}\text { PTF during } \\
\text { cutting }\end{array}$ & Aging & $\begin{array}{l}\text { PTF dur- } \\
\text { ing } \\
\text { aging }\end{array}$ & Beams tested \\
\hline \multirow[t]{2}{*}{ AS77 } & 8 & $524(100 \%)$ & 171 (32.6\%) & No & - & $178(34.0 \%)$ \\
\hline & & & & Yes & 0 & 175 (33.4\%) \\
\hline \multirow[t]{2}{*}{ AS } & 8 & $558(100 \%)$ & 272 (48.7\%) & No & - & $170(30.5 \%)$ \\
\hline & & & & Yes & 0 & $116(20.8 \%)$ \\
\hline \multirow[t]{2}{*}{ S77 } & 8 & $568(100 \%)$ & 302 (53.2\%) & No & - & $146(25.7 \%)$ \\
\hline & & & & Yes & 0 & $120(21.1 \%)$ \\
\hline
\end{tabular}

according to the following scores: (a) adhesive (along the ceramic/ cement interface); (b) cohesive with ceramics; (c) cohesive with cement; and (d) mixed (adhesive failure along the ceramic/cement failure interface + cohesive with resin).

\subsection{Statiscal analysis}

Two statistical analyses were used to analyze the $\mu$ TBS results. One-way ANOVA and Tukey's test ( $\alpha=0.05)$, with the means of the repetitions (beams) from each block, were applied for treatment comparison. Weibull analysis with a Maximum Likelihood (MLD) model with a $95 \%$ confidence interval $(\mathrm{CI})$ was used to compare the aged and non-aged groups [22]. The values of Weibull modulus $(m)$ and characteristic strength $\left(\sigma_{0}\right)$ were obtained to verify whether the aging process influences the bond strength survival of the groups. Only the bond strengths of specimens with adhesive failure were considered in the statistical analyses.

\section{Results}

The number of blocks and beams from each experimental group, the number and percentage of pre-test failures (PTF) during cutting and during aging, and the total number of beams tested are shown in Table 2. Among the groups, Group AS77 had the lowest PTF number during the cutting, followed by AS and S77. There was no PTF during the aging process. Tables 3 and 4 present the comparison between the non-aged and aged groups, respectively. Adhesive failure along the ceramic/cement interface was the predominant failure mode for all groups. This failure mode is shown in Figs. 1 and 2. AS and S77 had higher rates of cohesive failure than AS77, for both situations. The comparison of the $\mu$ TBS means of the adhesive failures showed no significant difference $(p=0.255)$ for the non-aged groups (Table 3$)$. The S77 group after aging was significantly inferior to AS77 and AS $(p=0.005)$. As shown in Figs. 3-5, there was no difference in the Weibull modulus $(m)$ and characteristic strength $\left(\sigma_{0}\right)$ of the aged and non-aged specimens, for all comparisons. The similarity of the $m$ values is indicated by the overlapping confidence intervals. The characteristic strength value of S77 (aged) was the lowest among the groups, and the $m$ value of AS (nonaged) was the lowest.

Table 3

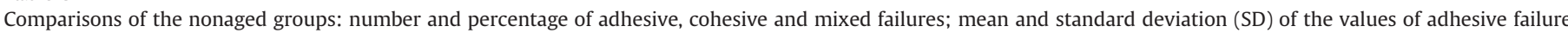
and $p$-value for the comparison*; Weibull modulus $(m)$ and characteristic strength $\left(\sigma_{0}\right)$ values with the confidence intervals $(\mathrm{CI})$.

\begin{tabular}{|c|c|c|c|c|c|c|}
\hline \multirow[t]{2}{*}{ Group } & \multicolumn{3}{|c|}{ Type of failure } & \multirow[t]{2}{*}{ Bond strength ( ${ }^{*} p^{=}$0.255) } & \multicolumn{2}{|c|}{ Weibull analysis } \\
\hline & Adhesive & Cohesive & Mixed & & $m$ (CIs) & $\sigma_{0}(\mathrm{CIs})$ \\
\hline AS77 & $144(80.9 \%)$ & $8(4.5 \%)$ & $26(14.6 \%)$ & $19.1(7.6)$ & $2.9(2.5-3.2)$ & $21.9(20.6-23.1)$ \\
\hline AS & $133(78.2 \%)$ & $36(21.7 \%)$ & $1(0.1 \%)$ & $18.5(11.0)$ & $1.9(1.6-2.3)$ & $21.8(19.5-24.2)$ \\
\hline S77 & $100(68.5 \%)$ & $36(24.6 \%)$ & $10(6.9 \%)$ & $18.0(7.8)$ & $2.6(2.2-3.0)$ & $20.7(18.9-22.2)$ \\
\hline
\end{tabular}

" The bond strength data of the groups were not statistically different (One-way Anova comparison, $\alpha=0.05$ ).

Table 4

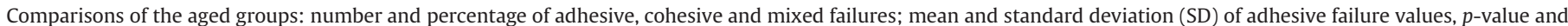
grouping information*; Weibull modulus $(m)$ and characteristic strength $\left(\sigma_{0}\right)$ values with the confidence intervals $(\mathrm{CI})$.

\begin{tabular}{|c|c|c|c|c|c|c|}
\hline \multirow[t]{2}{*}{ Group } & \multicolumn{3}{|c|}{ Type of failure } & \multirow[t]{2}{*}{ Bond strength ( $\left.{ }^{*} p=0.005\right)$} & \multicolumn{2}{|c|}{ Weibull analysis } \\
\hline & Adhesive & Cohesive & $m$ (CIs) & & $m$ (CIs) & $\sigma_{0}(\mathrm{CIs})$ \\
\hline AS77 & $146(83.4 \%)$ & $17(9.7 \%)$ & $12(6.9 \%)$ & $16.8(7.4) \mathrm{a}$ & $2.5(2.2-2.8)$ & $19.1(17.7-20.3)$ \\
\hline AS & $85(73.3 \%)$ & $26(22.4 \%)$ & $5(4.3 \%)$ & $16.6(7.8) \mathrm{a}$ & $2.2(1.8-2.6)$ & $18.5(17.0-20.6)$ \\
\hline S77 & $91(75.8 \%)$ & $26(21.6 \%)$ & $3(2.6 \%)$ & $14.5(7.3) \mathrm{b}$ & $2.1(1.8-2.5)$ & $16.5(14.8-18.2)$ \\
\hline
\end{tabular}

* Groups with the same letter were not statistically different (Tukey test; $\alpha=0.05$ ). 


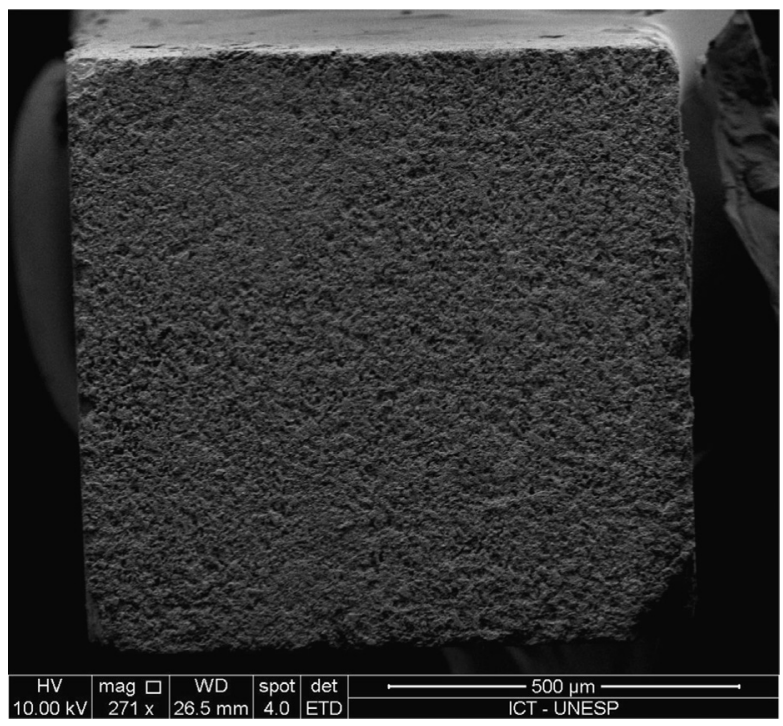

Fig. 1. SEM photomicrograph (ETD detector, $271 \times$ ) of a ceramic slice from group AS77 with adhesive failure mode. This failure mode was predominant for all groups.

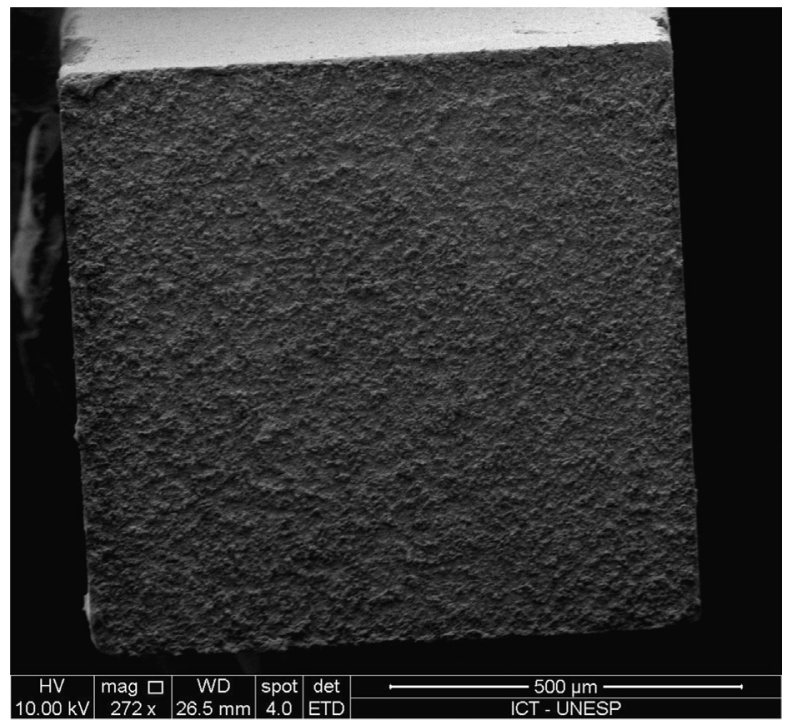

Fig. 2. SEM photomicrograph (ETD detector, $272 \times$ ) of a resin slice from group AS77 with adhesive failure mode. This failure mode was predominant for all groups.

\section{Discussion}

Adhesion to silica-based ceramics has been studied and improved in recent years $[5,6,8]$. Although the conventional treatment involving hydrofluoric acid + silane provides acceptable bond strength between ceramic and resin cement [3,5], hazardous effects of the acid have led to studies to find alternative treatments for ceramic surfaces $[3,5,6,8,12,17]$. The findings of this study suggested that the three tested treatments, one excluding the hydrofluoric-acid-etching step, provided similar bond strengths to ceramic without aging by thermocycling. However, after the aging process, the results of the non-etched group were statistically lower compared with those of the etched groups, leading to partial rejection of the first study hypothesis.

Hydrofluoric acid etching of silica-based ceramics has the capacity of reacting with the glassy matrix to form a soluble hydrofluorosilic acid, which can be rinsed off. This reaction results in micromechanical retention on the surface and increases surface

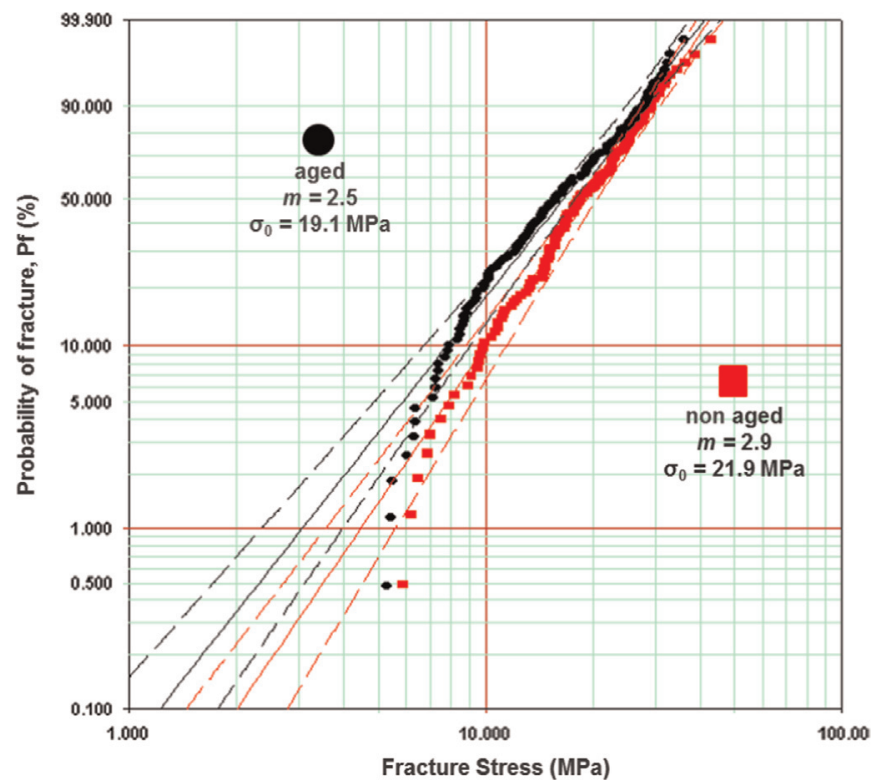

Fig. 3. Weibull comparison (Maximum Likelihood analysis - MLD) of the aged and non-aged AS77 groups.

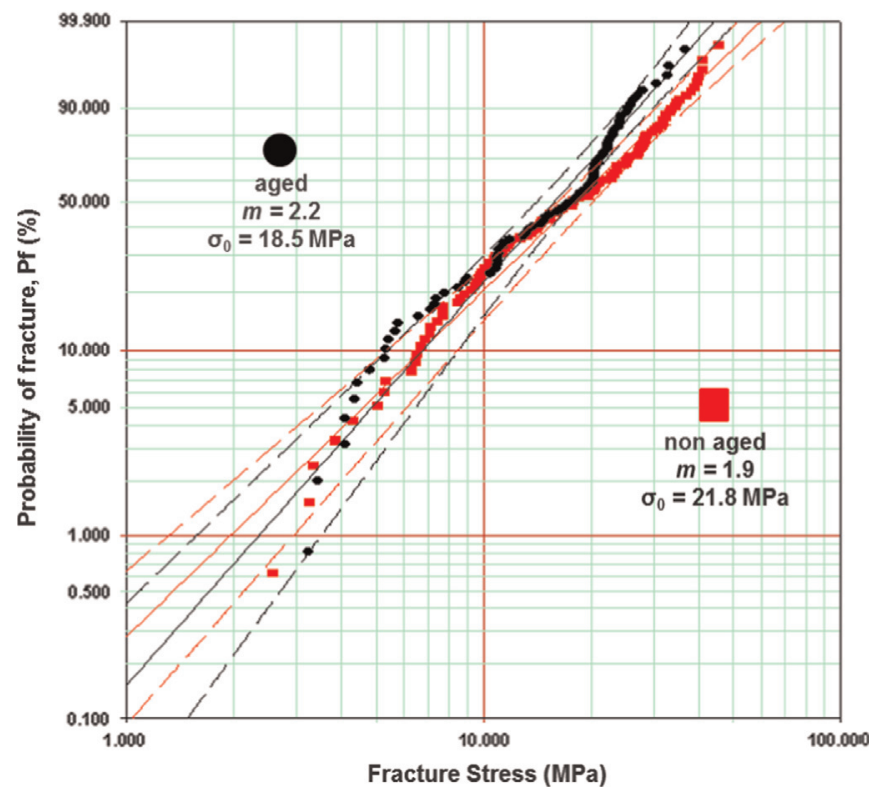

Fig. 4. Weibull comparison (Maximum Likelihood analysis - MLD) of the aged and non-aged AS groups.

energy [3]. Previous studies have reported higher bond strength of the ceramic-resin interface with HF rinsing compared with no rinsing [23] or even with sandblasting or surface-grinding [6]. The stability of the bond strength for the etched specimens in this study is in agreement with the results of a previous study [6] where the interface was not affected by 1 -year storage. Moreover, the similarity between the $m$ values of the aged and non-aged groups suggests that the reliability of the interface after HF etching was not affected by thermocycling.

Previous studies have shown the benefits of heat treatment for the bond strength between ceramic and cement $[5,6,8,17]$. The immediate bond strength values found in this study confirmed these findings, since the silanized + heated group (S77) promoted similar bond values to groups with hydrofluoric acid etching (AS and AS77). Although the heat treatment consisted of a warm air 


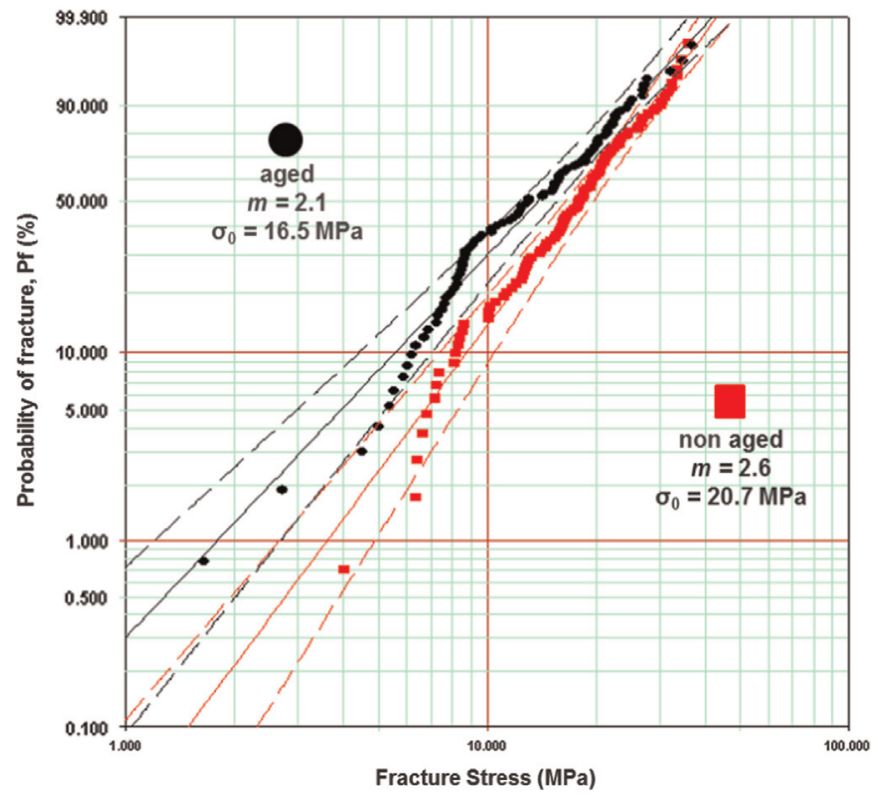

Fig. 5. Weibull comparison (Maximum Likelihood analysis - MLD) of the aged and non-aged $\mathrm{S} 77$ groups.

stream $\left(100^{\circ} \mathrm{C}\right)$ in some studies [5,6], in the present study, we attempted to isolate the temperature factor by using an oven. The heat treatment eliminated the silane by products and helped complete the reaction between silane and silica [8]. The association of the two treatments of this study (HF acid etching and heat) did not affect the $\mu$ TBS results. However, it did result in lower PTF rates during specimen sectioning, which suggests an improvement in the union between materials and can be used to optimize the clinical results during cementation.

A previous study by this research group [17] showed that heat treatment of the silane at $77^{\circ} \mathrm{C}$ had a positive effect on interfacial bond strength, which was not affected by mechanical cycling $(200,000$ cycles). Once the previously selected mechanical fatigue regimen was found not to affect the bond strength of the system [17], the influence of this heat treatment was tested after thermocycling. The aim of this aging process was to induce some contraction/expansion stress at the interface as a result of the thermal coefficient differences of the materials [9] that could cause crack propagation among them. Although different thermocycling profiles have been reported in the literature [24-27], this study used 12,000 cycles. This protocol did not significantly affect the $m$ and $\sigma$ of the groups, but did reduce the mean values of the S77 group, which was significantly lower compared with the others. Moreover, the S77 group had the greater difference between the $\sigma$ values compared (aged and non-aged), casting doubt concerning the long-term success of the treatments excluding acid etching. The similarity between the $m$ of the groups suggests that aging did not affect the survival of the interfaces.

In contrast to previously reported literature reports [5,6,8,17], this study considered only the specimens with adhesive failure for statistical analyses, since pure adhesive failures express the actual situation of the tested interfaces. The high rate of pre-test failures during the cutting procedure is a limitation of this study, but it did not affect the statistical analysis, since the number of specimens tested was sufficient to find a difference between the aged groups.

Although producing significantly different results after thermocycling, HF use is still questionable, since the results were not markedly different from those in the group treated solely with silane and heated. Thus, clinical trials are necessary to show if there are clinically relevant differences between these protocols.

\section{Conclusions}

Heat treatment of silanized feldspathic ceramic (non-acidetched surface) provided similar bond strength compared to the traditional hydrofluoric-acid-etching treatment before aging and lower bond strength after aging, partially rejecting the first hypothesis. The combination of the hydrofluoric-acid-etching and the heat treatment did not improve the bond strength, accepting the second study hypothesis. The thermocycling regimen selected for this study did not affected the reliability of the groups, accepting the third study hypothesis.

\section{Acknowledgments}

FAPESP (Sao Paulo State Foundation, Brazil) supported this study (Grant \# 2012/10573-5).

\section{References}

[1] Blatz MB, Sadan A, Kern M. Resin-ceramic bonding: a review of the literature J Prosthet Dent 2003;89:268-74.

[2] Yadav S, Upadhyay M, Borges GA, Roberts E. Influence of ceramic (feldspathic) surface treatments on the micro-shear bond strength of composite resin. Angle Orthod 2010;80:765-70.

[3] Lung CYK, Martinlinna JP. Aspects of silane coupling agents and surface conditioning in dentristry: an overview. Dent Mater 2012;28:467-77.

[4] Della Bona A, van Noort R. Ceramic surface preparation for resin bonding. Am J Dent 1998;11:276-80.

[5] Fabianelli A, Pollington S, Papacchini F, Goracci C, Cantoro A, Ferrari M, et al. The effect of different surface treatments on bond strength between leucite reinforced feldspathic ceramic and composite resin. J Dent 2010;38:39-43.

[6] Roulet JF, Söderholm KJM, Longmate J. Effects of treatment and storage conditions on ceramic/composite bond strength. J Dent Res 1995;74:381-7.

[7] Della Bona A, Anusavice KJ, Mecholsky Jr. JJ. Failure analysis of resin composite bonded to ceramic. Dent Mater 2003;1:693-9.

[8] Hooshmand T, van Noort R, Keshvad A. Bond durability of the resin-bonded and silane treated ceramic surface. Dent Mater 2002;18:179-88.

[9] Amaral R, Ozcan M, Bottino MA, Valandro LF. Resin bonding to a feldspar ceramic after different ceramic surface conditioning methods: evaluation of contact angle, surface $\mathrm{pH}$, and microtensile bond strength durability. J Adhes Dent 2011;13:551-60.

[10] Leite F, Özcan M, Valandro LF, Amaral R, Bottino MA, Kimpara ET. Effect of the etching duration and ultrasonic cleaning on microtensile bond strength between feldspathic ceramic and resin cement. J Adhes 2013;89:159-73.

[11] Saavedra G, Ariki EK, Federico CD, Galhano GA, Zamboni S, Baldissara P, et al Effect of acid neutralization and mechanical cycling on the microtensile bond strength of glass-ceramic inlays. Oper Dent 2009;34:211-6.

[12] Shen C, Oh W, Williams R. Effect of post-silanization drying on the bond strength of composite to ceramic. J Prosthet Dent 2004;91:453-8.

[13] Papacchini F, Monticelli F, Hasa I, Radovic I, Fabianelli A, Polimeni A, et al. Effect of air-drying temperature on the effectiveness of silane primers and coupling blends in the repair of a microhybrid resin composite. J Adhes Dent 2007;9:391-7.

[14] de Carvalho RF, Martins ME, de Queiroz JR, Leite FP. Ozcan influence of silane heat treatment on bond strength of resin cement to a feldspathic ceramic. Dent Mater J 2011;30:392-7.

[15] Sakai M, Taira Y, Sawase T. Silane primers rather than heat treatment contribute to adhesive bonding between tri-n-butylborane resin and a machinable leucite-reinforced ceramic. Dent Mater J 2011;30:854-60.

[16] Queiroz JR, Souza RO. Nogueira Junior L, Ozcan M, Bottino MA. Influence of acid-etching and ceramic primers on the repair of a glass ceramic. Gen Dent 2012;60:79-85.

[17] Corazza PH, Cavalcanti SC, Queiroz JR, Bottino MA, Valandro LF. Effect of postsilanization heat treatments of silanized feldspathic ceramic on adhesion to resin cement. J Adhes Dent 2013;15:473-9.

[18] Olmos D, Gonzáles-Benedito J, Aznar AJ, Baselga J. Hydrolytic damage study of the silane coupling region in coated silica microfibres: $\mathrm{pH}$ and coating type effects. J Mater Process Technol 2003;143-144:82-6.

[19] Melo RM, Valandro LF, Bottino MA. Microtensile bond strength of a repair composite to leucite-reinforced feldspathic ceramic. Braz Dent J 2007; 18:314-9.

[20] Schrader ME. Radioisotopic studies of bonding at the interface. J Adhes 1970:2:202-12.

[21] Monticelli F, Toledano M, Osorio R, Ferrari M. Effect of temperature on the silane coupling agents when bonding core resin to quartz fiber posts. Dent Mater 2006;22:1024-8.

[22] Eckert GJ, Platt JA. A statistical evaluation of microtensile bond strength methodology for dental adhesives. Dent Mater 2007;23:385-91. 
[23] Nagayassu MP, Shintome LK, Uemura ES, Araújo JE. Effect of surface treatment on the shear bond strength of a resin-based cement to porcelain. Braz Dent J 2006; 17:290-5.

[24] Guarda GB, Correr AB, Gonçalves LS, Costa AR, Borges GA, Sinhoreti MA, et al. Effects of surface treatments, thermocycling, and cyclic loading on the bond strength of a resin cement bonded to a lithium disilicate glass ceramic. Oper Dent 2013;38:208-17

[25] Baur V, Ilie N. Repair of dental resin-based composites. Clin Oral Investig $2013 ; 17: 601-8$.
[26] Vanderlei A, Passos SP, Özcan M, Bottino MA, Valandro LF. Durability of adhesion between feldspathic ceramic and resin cements: effect of adhesive resin, polymerization mode of resin cement, and aging. J Prosthodont 2013;22:196-202.

[27] Peumans M, Hikita K, De Munck J, Van Landuyt K, Poitevin A, Lambrechts P, et al. Bond durability of composite luting agents to ceramic when exposed to long-term thermocycling. Oper Dent 2007;32:372-9. 